\title{
Reflections on the Concept Transformation and Implementation Strategies of College Volleyball Education
}

\author{
Liaoning Nomal University Liu Xian 116029
}

\begin{abstract}
The concept of college volleyball education directly impacts the long-term development of China's sports. Based on the current situation of the college volleyball teaching, this essay put forward three transformations of its teaching concept: transforming the education from examination-oriented to quality-oriented; transforming the compulsory teaching of conductive to learning teaching of interest, and transforming the rigid stiff teaching to the developing innovative teaching, so as to construct an optimized education system of human oriented, to improve the practical value of volleyball teaching with modern innovation ideas and to implement strategies to diversified the volleyball education with the idea of resource sharing.
\end{abstract}

Key words: colleges, volleyball education concept, strategies

\section{The current situation of college volleyball teaching}

Physical education in colleges and universities is now on the calendar with the rapid development of China's sports in recent years, and attention has been largely paid to volleyball teaching.

Achievements had been obtained in volleyball teaching from the development process of China's volleyball teaching. For one thing, volleyball teaching in colleges and universities cultivated the sports consciousness and the students' self-confidence and pride.

An another thing is that college students can improve their own cognitive abilities to volleyball courses by learning related theoretical knowledge and thus promoting the continuous development of the volleyball career combining theories with practice.

The professional theoretical knowledge of volleyball was summarized from the teaching experiences. Cultivation on the professional theoretical knowledge is crucial to college students. Centered on the professional theoretical knowledge, students can then have a systematic understanding on the volleyball education. From the current situation of the volleyball teaching in China's colleges, this part of teaching content is indispensable.

Chart 1 Statistics of the theory selections in China's colleges

\begin{tabular}{cc}
\hline Theoretical teaching content & Schools (number) \\
\hline Overviews on volleyball as a sport & 18 \\
The latest achievements and development trends of volleyball & 10 \\
Basic theories of the volleyball skills and tactics & 22 \\
Teaching and training on volleyball skills and tactics & 13 \\
The organization and management of school volleyball teams & 11 \\
Guiding principles for matches & 14 \\
\hline
\end{tabular}


What can be seen from Chart 1 is that China's colleges have a rather scientific distribution in the selection of theoretical contents which now mainly contains sixteen different parts.

Most colleges are paying attention to three parts: basic theories of volleyball skills and tactics, the teaching and training on volleyball skills and tactics and the competition rules, scheduling and refereeing work of volleyball. From the three main teaching contents, emphases of teaching settings are now on the common senses of volleyball as a sport.

It is undoubtedly a good choice for college students in ensuring them a basic understanding and cognition on volleyball teaching. On the contrary, courses on the studies of middle school volleyball texts and teaching methods of deeper level and other forms of volleyball sports are now marginalized.

Chart 2 Statistics of the skill contents selection in China's colleges

\begin{tabular}{cc}
\hline Details of contents & Schools (Number) \\
\hline Amalleyball teaching abilities & 18 \\
Abilities of contest organization and refereeing & 11 \\
Abilities of contest and practice & 13 \\
Abilities of creating volleyball games & 12 \\
Abilities of organizing extra curriculum volleyball activities & 5 \\
Technical statistics & 2 \\
Spot commands abilities & 4 \\
\hline
\end{tabular}

It can be seen from the Chart 2 showing the statistics of the skill contents selection in China's colleges that the top three are the abilities of volleyball teaching, contest organization and refereeing, competition and practice. There is no difficulty finding the emphases colleges had on cultivating the practical abilities in volleyball skills training while neglecting the cultivation on extra curriculum volleyball activities, spot commands abilities and technical statistics.

Therefore from the Chart 1 and 2, obvious emphases from China's colleges in volleyball teaching had resulted in both advantages and disadvantage either in theoretical or skill knowledge. 
The disadvantages are that while the theoretical knowledge cultivation is relatively rigid, there is an absence of systematicness in skill cultivating. To coordinate the many problems in China's college volleyball education and to promote its further development, transformations of the teaching theories are the top priority.

\section{Transformations of the college volleyball education theories}

\subsection{Transforming the education from examination oriented to quality oriented}

Affected by the college education system, China's college volleyball education theories fail to keep up with the times and have low efficiency which in some sense related with examination oriented teaching ideas.

The examination oriented teaching theory, mainly refers to the overemphasis on students' academic records, neglected the cultivation on students' qualities and abilities and failed to embody their comprehensive abilities in all directions.

From the development of China's college volleyball teaching in recent years, it is obvious that the examination oriented education has caused great resource waste.

Therefore the colleges are paying attention to the transformations of education theories in actively exploring and studying the quality education theory to direct the college students in the right direction and to improve the comprehensive quality of the college volleyball education.

In a sense, transformations of education from examination oriented to quality oriented are shown in the following points.

The first is the emphases from scores only to comprehensive qualities, which means that the college volleyball education now have a broader target not only the students' performance in volleyball and the scores are not the top priority.

Once transformed into the quality oriented education, the students' comprehensive qualities would receive recognition from more people as well as the colleges' comprehensive abilities in volleyball.

The second is the transformation of teaching resources from one linear to a shared one. The resource utilization rates as well as the teaching effects are improved compared with the conventional teaching resources.

Thus in this point of view, the transformations of teaching theories from examination oriented education to quality oriented are significant and make practical sense to the college volleyball teaching.

\subsection{Transforming the conductive compulsory teaching to learning teaching with interest}

College education, an important component of China's education, plays a crucial role in its development. Volleyball teaching, an important course of college physical education, direct effects the long term development of China's college physical education.

Converting from the conductive compulsory teaching to the interest oriented learning teaching reflects the transformation of the college volleyball teaching theory. The conductive compulsory teaching, regarding teachers as the subject of initiative and greatly restricted the students, who were the main bodies of passive learning, lacks necessary objectives.

The learning teaching with interest, however, gives students more developing space compared with the conductive compulsory teaching mode and explores their potential to improve their comprehensive abilities.

For one thing, students are transforming from passive learning to active learning. This means that students are now motivated under the transition of teaching theories to learn more about volleyball teaching and to distinguish the real connotation of it. 
The development of the college volleyball teaching is therefore getting easier and their theoretical knowledge is getting richer. It illustrates the easier social acceptance and popularization of college volleyball teaching compared with the traditional passive learning.

The other thing is that teachers are getting gradually less teaching pressures. Teachers faced arduous teaching pressures in the traditional passive learning theories in instructing the basic volleyball curriculum as well as passively leading the students to realize the importance of the volleyball teaching.

Under the new teaching theories, teachers need not to lead the students to volleyball learning on purpose since students’ initiatives are now fully motivated. This will also help reduce the teaching pressure.

\subsection{Transforming the rigid stiff teaching to the developing innovative teaching}

Another reflection on the college volleyball teaching theories is the transformation from the rigid stiff teaching to the developing innovative teaching. The rigid stiff teaching in volleyball has no creativity and is static in teaching ideas and sticking to relative knowledge on the textbooks, the teaching methods are stodgy and doctrinal.

The developing innovative teaching keeps up with the times in theory, and is creative in teaching methods to improve the teaching quality to the most.

From the development of China's volleyball teaching in recent years, this developing innovative teaching has obtained brilliant achievements in improving the whole quality of college volleyball teaching system and reforming the teaching methods of college volleyball curriculum.

The following points reflect the transformation from the rigid stiff teaching to the developing innovative teaching.

One is the shift from the single teaching of doctrinarism to multimedia teaching which means that China's volleyball teaching is now developing in a diversified trend compared with the doctrinal single teaching.

Multimedia instruction is now applied in the class of volleyball teaching in China's colleges with more colorful teaching methods and more lively and vivid teaching contents.

The other one is the more diversified teaching resources. Presently, many colleges in China are equipped with more diversified volleyball teaching resources. College teachings, now not rely only on blackboard but diversified teaching resources, make remarkable achievements.

In a sense, therefore, the transformation from rigid stiff teaching to the developing innovative teaching is a progress in China's colleges and keeps pace with the times.

\section{Implement strategies of college volleyball teaching}

\subsection{Constructing an optimized education system of human oriented}

Sticking to the human-oriented teaching theory is the top priority of China's college education as well as the volleyball major. As one of the main courses of China's physical curriculum, the volleyball major plays a significant role in the development of China's physical careers.

Upholding the human-oriented teaching theory requires colleges to respect the students' wishes and to be responsible for them to improve their overall qualities.

The first is to well-organize the teaching curriculum. There are many problems exit in the current China's volleyball teaching curriculum caused mainly by the imperfect teaching system. One thing is that the marginalization of many volleyball courses leads to the colleges' neglect to related courses, leaving many a disadvantages for volleyball teaching. 
The second is the teaching theories transformation which is especially significant to college volleyball teaching. Backward ideas coexist with significant improvements in China's volleyball teaching in recent years. Thus transformation in teaching theories is indispensible in optimizing the volleyball teaching system and only then can we promote the long term development of college volleyball teaching.

\subsection{Improving the practical value of volleyball teaching with modern innovation ideas}

Adhering to advanced ideology of the times is crucial to the current college education development and the requirement adapting to the modern social trend. One of main targets of China's college education is to find out the integration point of adapting to the modern society development and the college graduates.

China's college physical teaching directly links with the social sports. Thus for college graduates who would mostly participate in the practical activities of social sports, their knowledge and abilities in school will in a sense directly influence their abilities adapting to them.

The indispensable strict teaching activities on college students are the important reflections in realizing the practical value of volleyball teaching.

The first is simplifying and reorganizing the inner teaching. For college students majoring in volleyball, learning and mastering necessary knowledge of volleyball is the basic requirements and the first step stepping into the society.

To innovate the teaching in a diversified way, colleges should have inner simplification and reorganization, namely to reform in ideology, to adhere to the idea of modern innovation and to find out the integration point with the society.

The second is to improve the practical values of volleyball teaching to the largest extent. Volleyball as a major, leaving its graduates great pressure, is less popular compared with other majors due to its little help to employment.

Colleges then should set the criteria of volleyball teaching on the target of necessary social employment and cultivating professional talents that meet the needs of the society. It means that colleges should keep closely with the development of society in volleyball curriculum setting to settle the problems of the graduates' employment.

\subsection{Implementing strategies to diversified the volleyball education with the idea of resource sharing}

One of the great advantages of education is resource without which the development of education would fall into a difficult situation. For China's college volleyball teaching, abundant resources are the key to its development. Chinese government is paying increasing attention to the sports career in recent years and the college physic education is therefore in progress and development. Meanwhile, the abundant teaching resources in China's college volleyball education promote its rapid development to a certain extent.

The methods of college volleyball education are now not single with more diversified teaching methods and more perfect physical facilities and the volleyball teaching in colleges is now becoming more colorful.

From the current situation of China's college volleyball teaching, several acquirements should be strictly meet to develop and diversify China's college volleyball teaching to the largest extent.

The first thing is to set up the idea of resource sharing. Active popularization of education with the power of media is inevitable along with the cooperation and education resources sharing of different colleges.

Another thing is to implement the practicality of volleyball teaching. Theories can be useful only when applied to practice. So volleyball teachings in colleges should adhere to the teaching idea of applying the theories to practice to fully exploit their function. 
Above all, China's colleges should build the ideas of resources sharing from the beginning to the end to use resources by resources and then diversify the volleyball teaching in improving its teaching quality at the same time.

\section{References}

[1] Liu Bin. Biomechanics Simulation of Volleyball Player in Jumping Spike[J]. Advanced Materials Research . 2012 (468)

[2] Salehifar,H. Visual Tracking of Athletes in Volleyball Sport Videos. Proceedings of the 2011 International Conference on Image Processing . 2011

[3] Yu,Guishen. The Application of Multimedia Technology in Action-oriented Instruction of Volleyball Course of Sports Majors in Institutions of Higher Learning. 2010 International Conference on E-Health Networking . 2010

[4] Liu,Minhang. Dynamic Research of Shandong Province Talented Volleyball Reserve Training Efficiency. 2nd International Conference on Information Science and Engineering . 2010

[5] Wang,Qiaoying. The Thinking on Teaching Reform of Volleyball Elective Course. Communications in Computer and Information Science. 2012 